\title{
ACTIVIDADES DEL PROGRAMA DE
RECURSOS NATURALES EN MATERIA DE CONSERVACIÓN Y USO SOSTENIBLE DE, RECURSOS
}

\section{Salvador Bautista Magallón}

Oficina Regional para América latina y el Caribe. México

A partir de la década de los 70 la conciencia ambiental a nivel mundial empieza a incrementarse. Es así que en 1972, en Estocolmo, Suecia, durante la Conferencia M undial de las $\mathrm{N}$ aciones U nidas sobreel M edio Ambiente H umano, se reconoce la necesidad de reorientar las políticas de crecimiento económico para cambiar los patrones de producción y consumo con alto costo ambiental y social.

Posteriormente, en la Conferencia de las $\mathrm{N}$ aciones U nidas sobre M edio Ambientey D esarrollo, celebrada en Río de Janeiro, Brasil, en junio de 1992, líderes de todo el mundo reconocieron la problemática ambiental que enfrenta el mundo, además de reconocer las desigualdades entre los países del hemisferio norte y los del hemisferio sur. Si bien durantela Conferencia hubo diferencias deopinión sobre aspectos relativos a patrones de consumo y estilos de vida, se lograron concertar acuerdos de suma importancia para Latinoamérica; por un lado se abrieron a la firma el Convenio sobre la D iversidad Biológica (CD B) y la Convención M arco sobre el Cambio Climático, y se negoció y estableció el documento final que daba pautas y compromisos a seguir por los $\mathrm{G}$ obiernos participantes en la Confe- rencia, la Agenda 21. Los países de Latinoamérica, a través de sus respectivos Gobiernos, reconocieron la importancia de esos acuerdos y han asumido los mandatos establecidos en los mismos.

Si bien la mayoría de los países Latinoamericanos han implementado acciones que responden a estos compromisos internacionales, informes de diversos organismos internacionales confirman que la presión sobrelos recursos naturales no ha cambiado y pone de manifiesto que el modelo económico seguido por los países latinoamericanos no es factible, lo cual, unido a las crisis políticas y financieras recurrentes, afectan directamente al uso racional de los recursos naturales, aspecto fundamental para al canzar el desarrollo sostenible en los países de Latinoamérica y el Caribe. Esta presión en los recursos se hace patenteen la alta tasa de deforestación y erosión de los suelos, en la sobre explotación y pérdida de los recursos acuícolas y terrestres, en la presión que ejerce y demanda el crecimiento urbano, la alta demanda de materia prima de la industria, tanto nacionales como transnacionales, por mencionar al gunos de los problemas que aquejan a la región. Ahora bien, estos patrones de demanda 
de recursos naturales también deterioran la calidad de vida de las poblaciones más desfavorecidas lo que ocasiona un círculo vicioso en el cual, los grupos humanos afectados, agravan el problema ambiental.

Ante estos esquemas el Programa de las $N$ aciones Unidas para el M edio Ambiente (PN U M A), a través de su Programa de Recursos N aturales de la $O$ ficina Regional para América Latina y el Caribe, busca que lasinstituciones decadanación responsables delaconservación y uso sostenible de los recursos naturales aumenten su capacidad institucional para que, por medio de la implementación de acciones regionales y de la promoción dela cooperación internacional, puedan dar respuestaa los problemasquecada uno deellosy la región enfrentan.

En la Primera Sesión del Consejo de Administración del PN U M A, celebrada en junio de 1973, el Plan de Acción para el M edio Ambientefue aprobado y en él la conservación y uso sostenible de la natural eza, la vida silvestre y los recursos genéticos son una prioridad. Esta prioridad toma mayor fuerza con la entrada en vigor del Convenio sobre la Diversidad Biológica (CDB), el cual tiene como principal objetivo la conservación y uso sostenible de la biodiversidad y todos sus componentes.

Para cumplir con el mandato establecido por el Consejo de Administración, responder a las necesidades de la Región y coadyuvar en la implementación y puesta en práctica del CDB, el PN U M A desarrolló un plan deacción llamado "Programa de Biodiversidad y Estrategia de Implementación" (PBEI). Este programa está basado en la consulta mundial hecha durante las negociaciones internacionales para la elaboración del CD B y fue desarrollado en conjunto con el Instituto de Recursos M undiales (W RI) y la Unión para la Conservación de la N aturaleza (UICN). El mismo fue dado a conocer en 1992.

EI PBEI establece lo siguiente: "Acciones efectivas para conservar la diversidad biológica deben tomar en cuenta el amplio espectro de causas de la pérdida de la misma y abarcar todas las oportunidades que los genes, especies y ecosistemas proveen para el desarrollo sostenible. Porquela principal meta de la conservación de la biodiversidad - apoyo al desarrollo sostenible protegiendo y aprovechando los recursos biológicos evitando disminuir la variedad de genes y especies o destrucción de ecosistemas 0 hábitats- es muy amplia, cual quier estrategia de conservación y uso sostenible de la diversidad biológica deben tener un enfoque amplio y diverso. Por eso el PBEI se enfoca en tres elementos básicos: preservar la biodiversidad, estudiarla y aprovecharla de una manera sustentable y justa."

Con esto en mente, el Programa de Recursos $\mathrm{N}$ aturales de la $O$ ficina Regional para América Latina y el Caribe del PNU M A, lleva a cabo actividades interdisciplinarias para implementar el PBEI, entre ellas podemos mencionar las siguientes.

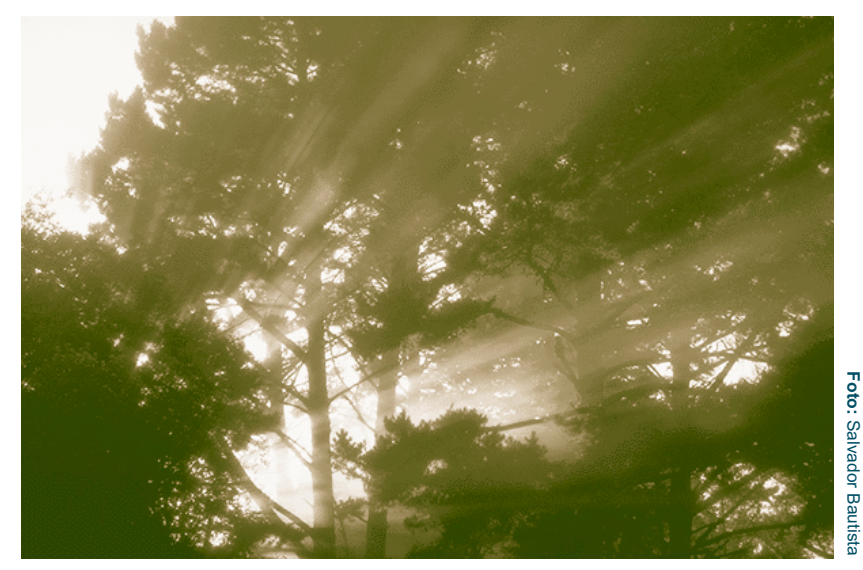

M arco Legal. En este rubro, el Programa de Re cursos $\mathrm{N}$ aturales, apoyándoseen el Programa de Legislación Ambiental de la 0 ficina Regional, apoya a los países de la Región para armonizar las políticas ambientales de los mismos para así cumplir con los compromisos asumidos por ellos en los Foros I nternacionales como son el CD B y otros Convenios y Protocolos Internacionales.

Economía de la Biodiversidad. EI PN U M A ha venido jugando un papel esencial en la elaboración de estudios y análisis de las políticas económicas vigentes y su impacto en la diversidad biológica. También cabe mencionar que en diversos seminarios y talleres regionales se han estado desarrollando técnicas de valoración de la biodiversidad para lograr así una buena administración dela misma, así como una repartición justa y equitativa de los beneficios del uso de estos recursos. 
Biotecnología. EI PN U M A, consciente de los riesgos queel mal uso de la biotecnología puede ocasionar a la biodiversidad y a la salud humana, desarrolló, con la ayuda de expertos de diversas nacionalidades, unas Directrices T écnicas de Seguridad en la Biotecnología, directrices que han supuesto un gran avance en la materia mientras que los Países Parte del Convenio negociaron y elaboraron el Protocolo de Bioseguridad, el cual, será presentado a firma el próximo mes de mayo del año en curso.

Evaluación, Investigación y Seguimiento de la Diversidad Biológica. En este punto, el PN U M A, en colaboración con expertos de todo el mundo, elaboraron el estudio más exhaustivo en materia de conservación y uso sostenible de la biodiversidad. La Evaluación M undial de la Biodiversidad es resultado de años de investigación y propone acciones concretas para la protección de la diversidad biológica. Además, han propuesto una serie de directrices que los tomadores de decisiones a nivel nacional, estatal y municipal pueden seguir para la implementación de actividades locales para la conservación y uso sostenible de los recursos naturales.

Conservación in-situ y ex-situ. EI PN U M A, bajo el mandato emanado por las autoridades medio ambientales de los países de la Región, ha colaborado con los M inisterios e Instituciones $\mathrm{N}$ acionales encargados de la conservación de los recursos naturales, en estudios, análisis y actividades que coadyuvan a la conservación de estos recursos. En este rubro, cabe mencionar proyectos de gran envergadura que en la actualidad el PN U M A, en colaboración con otros organismos internacionales, vienen implementando en la región latinoamericana, entre ellos tenemos los siguientes:

Corredor Biológico Mesoamericano. Esun proyecto de una gran cobertura ya que busca conectar los sistemas de áreas naturales protegidas desde el sur de M éxico hasta Panamá. El proyecto contempla actividades en diversas disciplinas como legislación ambiental y armonización de políticas; actividades de concienciación pública y educación ambiental, tanto formal como informal; evaluación y seguimiento del estado de los recursos; actividades de investigación y de intercambio de información, entre otras. El proyecto está coordinado por el PN U M A, el Programa de las N aciones U nidas para

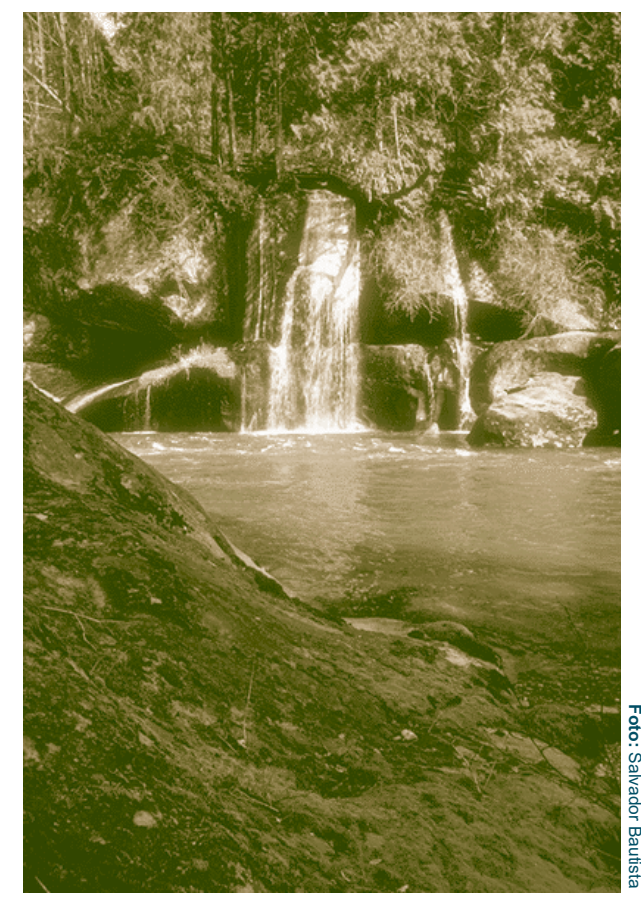

el Desarrollo (PNUD), el Banco M undial (WB) y la Comisión Centroamericana de Ambiente y $D$ esarrollo (CCAD), en colaboración con los M inisterios de M edio Ambiente de cada país y 0 rganizaciones N o-Gubernamentales con actividades relevantes en la materia.

Estudios y Estrategias N acionales de C onservación de la Diversidad Biológica. Los Países Parte del Convenio sobre la Diversidad Biológica de la Región, han asumido el compromiso de elaborar un Estudio $\mathrm{N}$ acional de País sobreel estado que guarda su biodiversidad y, además, en base a ese estudio, desarrollar una Estrategia de $\mathrm{N}$ acional de Conservación y U so Sostenible de la Diversidad Biológica. En este sentido, el PN U M A ha venido dando apoyo técnico e institucional a los países de la región para alcanzar estas dos metas y ha sido parte activa en los seminarios y talleres que cada país de la región ha llevado a cabo con sus expertos para darle seguimiento y forma a estos compromisos.

D iagnóstico G eneral de la Situación de los Bosques en América Latina. EI PN U M A, en colaboración con las autoridades ambientales de cada país, está elaborando un diagnóstico general de los bosques en la región, el cual dará las pautas para la elaboración de directrices y recomendaciones queayuden a los G obiernos de la Región a revertir los procesos de deforestación y mal uso de los bosques e 
implantar planes de manejo sostenibles y que beneficien a las comunidades que hacen uso de ellos.

Estudio sobre las Estrategias Ambientales para el Desarrollo Sostenible de América Latina y el Caribe: La Planificación Regional. En respuesta al mandato que los M inistros de M edio Ambientehan dado al PN U M A, se encuentra en desarrollo un re porte técnico que incluye un análisis general de indicadores ambientales y de desarrollo en la región que dará posteriormente base a una Estrategia de Planificación Bioregional que permita a los países de la región a alcanzar el desarrollo sostenible de manera conjunta.

Fortalecimiento de los Sistemas y Redes de Parques Nacionales y otras Áreas Protegidas en América Latina y el C aribe. En respuesta a la D ecisión 5 de la XI Reunión del Foro de M inistros de M edio Ambiente de América Latina y el $C$ aribe, celebrada en Lima, Perú, del 10 al 13 de marzo de 1998; el PN U M A, en colaboración con la O rganización de las $\mathrm{N}$ aciones U nidas para la Agricultura y la Alimentación (FAO), ha empezado el desarrollo conceptual de proyectos que buscan ampliar las áreas natural es protegidas en ecoregiones críticas latinoamericanas como los Andes y el Gran Chaco Americano, y reestructurar y ampliar la cobertura de las áreas naturales protegidas marino-costeras.

Además de estas actividades, el Programa de Recursos $N$ aturales del PN U M A da asistencia técnica a los Gobiernos en diversos tópicos de manejo de biodiversidad; participa activamente en los seminarios y talleres en materia de conservación y uso sostenible de la diversidad biológica que diversas instituciones, tanto Gubernamentales como Internacionales, convocan continuamente; diseña, elabora e implementa proyectos que el Fondo para el M edio Ambiente M undial (FM AM o GEF por sus siglas en inglés) financia.

Atendiendo a estas necesidadesel PN U M A, a través de su Programa de Recursos $\mathrm{N}$ aturales, cataliza actividades de conservación y uso sostenible de los recursos biológicos, fomenta la cooperación internacional y fortalece la participación de los gobiernos, la sociedad civil, las organizaciones no-gubernamentales y de la comunidad científica en la planeación, toma de decisiones e implementación de éstas y otras actividades que buscan que se alcance el desarrollo sostenible.

Para mayor información relativa a las actividades y programas que la O ficina Regional para América Latina y el Caribe del PN UM A lleva acabo en la región, proporcionamos los datos generales de la O ficina.

Programa de las $\mathrm{N}$ aciones U nidas para el M edio Ambiente

O ficina Regional para América Latina y el C aribe (ORPALC)

Blvd. de los Virreyes N o. 155, Col. Lomas de Virreyes

C.P. 11000

M éxico, D .F., M éxico

Tels: (+525) 20248 41, 2026394

Fax: (+525) 2020950

e-mail:Rolac@rolac.unep.mx

\section{Encargado del Programa de Recursos Naturales}

M. en C. Rafael Rodríguez Capetillo

Programa de las $\mathrm{N}$ aciones U nidas para el M edio Ambiente

O ficina Regional para América Latina y el C aribe

Blvd. de los Virreyes N o. 155, Col. Lomas de Virreyes

C.P. 11000

M éxico, D .F., M éxico

Tels: (+525) 20248 41, 2026394

Fax: (+525) 2020950

e-mail: recnat@rolac.unep.mx 